\title{
BEARING RESISTANCE OF CFRP WRAPPED CONCRETE
}

\author{
Jasim Ali Abdullah * ${ }^{*}$, Salem Yusuf Awad and Oday Asal Salih \\ College of Engineering, University of Mosul, Mosul-Iraq
}

(Accepted for Publication: December 29, 2020)

\begin{abstract}
This research investigates the localized loading resistance of concrete specimens wrapped using Carbon Fiber Reinforced Polymers (CFRP) to indicate the enhancement of load carrying capacity and ductility of adopted specimens. A series of concentrically localized loading tests have been performed to evaluate the behavior of concrete specimens (cylinders and cubes) confined by CFRP, especially the bearing strength. The strength of concrete (normal NS and high strength HS), the loading area and the length of the wrapping were used as parameters in this study. The failure modes and experimental results of confined concrete specimens were analyzed to show the parameters effect. The results proof that the confined specimens provide a higher bearing strength, as well as, the failure modes reveal that the full wrapping length of specimens is not required and the CFRP wrapping improve the ductility of the confined specimens while the length of the wrapping is ineffective especially with specimens loaded using small bearing area.
\end{abstract}

KEYWORDS: CFRP wrapping; Partial wrapping; Localized Loading Resistance; Failure Mode.

\section{INTRODUCTION}

$\mathbf{T}$ he building constructions included concrete filled tubular (CFT) and metallic structures became unsatisfactory structures due to its ageing and deteriorations are often reported (Abdullah et al (2010 \& 2011)). Therefore, actions like application of new materials and strengthening techniques become substantial to combat this problem. Even though the traditional strengthening techniques like steel jacketing and enlarging the section are successful in practice but indicate serious difficulties. In contrast, rehabilitation and strengthening methods using fiber reinforced polymer (FRP) composites provide one of the most effective means of confining existing reinforced concrete columns where the strength of these columns should be enhanced. The increasing of strength and ductility of confined concrete members is highly dependent on the performance of (CFRP) composite material, resulting in large energy dissipation capacity, so wrapped RC columns have larger bearing capacity and ductility. The strengthening technique using CFRP was introduced instead of the conventional methods such as tubed, CFST and steel jacketing of reinforced concrete (RC) members. The application of CFRP for the external strengthening of RC structures has been widely investigated and reported in the past few decades (Prabhu and Sundarraja (2013)).

Many studies have been conducted to explore the performance of concrete structures wrapped using CFRP especially with the compressive, flexural, and shear behaviors (Mirmiran et al (1998), Xiao and $\mathrm{Wu}$ (2000), Pantazopoulou et al (2001), Mukherjee (2004), Yalcin et al (2006), Ye et al (2003), Pankaj et al (2014)), Lima et al (2016), Al-Kamaki et al (2018) and Fathuldeen and Qissab (2019). Very little studies took the localized loading resistance as a target or

jassim24676@uomosul.edu.iq;_sua269@gmail.com;_ odaycivileng@uomosul.edu.iq $788^{*}$ Corresponding author: College of Engineering, University of Mosul, Mosul, Iraq 
enhancing it using CFRP wrapping. So, this paper attempts to introduce an extensive study to explain the effect of CFRP wrapping on the bearing strength of concrete.

Park et al (2008) conducted an experimental study to explore the performance of applying the narrow strips of CFRP laminates. The adopted specimens having different spacing and width of CFRP wrapping strips were tested under compressive loading. The effects of several parameters were investigated, such as spacing, spliced length, number of layers, and sectional area of the CFRP laminates. Constitutive models of concrete confined by narrow strips of CFRP laminates were proposed. Khan and Zafar (2010) conducted an experimental research on the bearing axial compressive strengths of CFRPwrapped concrete cylindrical specimens made of low strength concrete $(21 \mathrm{MPa})$. Various wrapping types were used to indicate the effect of CFRP-wrapping on the compressive strength of concrete. The results indicate that the bearing strength of CFRP-wrapped concrete was improved in all wrapping types and the confinement of concrete using strips of CFRP is the best method to enhance the strength of concrete.

Ravindrarajah and Reinaldy (2010) reported experimental works on the bearing strength of wrapped concrete using CFRP. The parameters of the study included the bearing strength ratio and bearing shape ratio. The results showed the bearing strength of the concrete mold is enhanced by up to $74 \%$ due to CFRP confining. It was depicted that the bearing area shape had minor effect on the bearing strength of concrete. Khairallah (2013) conducted an experimental research to investigate the mechanical performance of CFRP confined RC columns cast with self-compacted and normal concrete under concentric axial loading. The test results revealed that the failure modes of both types of specimens were similar and the confinement was effective with specimens made using lower normal concrete strength. It is also depicted that the wrapping technique may have a small effect on the confined column capacity but the desired effect is to enhance the ductility.

In (2018), Sadeghian and Fillmore conducted an experimental research to investigate the strain distribution of the unidirectional basalt FRP (BFRP) wrapped concrete specimens. The number of wrapping layers and the hoop strain caused due to the axial compression were used as parameters in their study. They concluded that the maximum hoop strain doesn't necessarily lead to rupture the BFRP wrapping. Also, it was indicated that the resistance of plain concrete increased as the number of wrapping layers increased. Moretti (2019) experimentally examined the jacket schemes and overlap configurations of small scale concentrically axially loaded CFRP confined plain concrete columns. The results depicted that the most cost effective jacket configuration among the examined specimens is for one layer of FRP wrapping, the overlap length of square columns in the corner or along the side isn't seem to affect the confining performance and the presence of CFRP wrapping parallel to the columns axis enhances the concrete strength. Souza et al (2019) proposed a procedure for repairing and strengthening the damaged RC corbel loaded using concentrated compression. The corbel was suffered to concrete spalling off. The solution concerned a limited repair with a polymeric mortar then strengthening using CFRP wrapping.

The present study is performed to investigate the performance of confined cylinders and cubes made of normal and high strength concrete. The adopted specimens are tested under localized compressive loading. To feed the knowledge regarding, the effect of wrapping length on the confining of cylinders made of normal and high strength concrete was used as a parameter. The ratio of bearing shape is also used as a parameter in this study.

jassim24676@uomosul.edu.iq;_sua269@gmail.com;_ odaycivileng@uomosul.edu.iq

* Corresponding author: College of Engineering, University of Mosul, Mosul, Iraq 


\section{EXPERIMENTAL PROGRAM}

The shapes of examined specimens were standard cylinder (diameter $150 \mathrm{~mm}$ and height $300 \mathrm{~mm}$ ) and cube (size $150 \mathrm{~mm}$ ). The specimens distributed to groups depends on the parameters of the study. Each group of cylindrical specimens consists of four specimens including wrapped and exposed cylinders. The cubic specimens groups include two specimens (wrapped and exposed). The main experimental parameters were length of wrapping and concrete strength. Three different length of wrapping $(100,200$, and $300 \mathrm{~mm})$ and two grades of concrete (Normal and High Strength) were adopted herein. Single layer of wrapping was used in the confining of adopted specimens with adequate overlap of ends. The epoxy (Strongcoat 400) was used in the applying of confining and the curing time of adhesion was about ten days before testing. The limited area of compressive loading was also taken as a parameter in this study. The cylinders were applied to localized circular loading area, while the cubes were loaded using a limited square area.
Four size of loading area (both the circular and square area) 50, 75, 100 and $150 \mathrm{~mm}$ were adopted herein. The tested specimens were classified to nine groups according to its shape, compressive strength, length of wrapping and the loading area. The specimen's properties and wrapping details are summarized in (Table 1and Figure 1). The tests were conducted in the Constructional Materials Testing Lab in the University of Mosul. After casting the concrete, the partial curing was used about two months the to develop the strength of concrete. The test was conducted for all the specimens using a hydraulic compression machine with maximum capacity arrived to $2000 \mathrm{kN}$. After installing the unit of test and putting the specimen under the loading actuator, the rate of loading on the concrete core was $0.8 \mathrm{MPa} / \mathrm{sec}$ arrived to yield point in the elastic range. To investigate the response of softening and failure mode of the specimens, the bearing load was slowly and continuously applied near the peak load. The test setup is shown in Figure (1).

Table (1): Details of Tested Specimens Penetration

\begin{tabular}{|c|c|c|c|c|c|}
\hline Group & Specimen & Type & fc' (MPa) & Size of Loading Area (mm) & Length of wrapping by CFRP (mm) \\
\hline \multirow[t]{4}{*}{ Group-1 } & CYN-50-A* & Су. $150 * 300 \mathrm{~mm}$ & 36.8 & 50 & 0 \\
\hline & CYN-50-B & Су. $150 * 300 \mathrm{~mm}$ & 36.8 & 50 & 100 \\
\hline & CYN-50-C & Су. $150 * 300 \mathrm{~mm}$ & 36.8 & 50 & 200 \\
\hline & CYN-50-D & Су. $150 * 300 \mathrm{~mm}$ & 36.8 & 50 & 300 \\
\hline \multirow[t]{4}{*}{ Group-2 } & CYN-100-A & Су. $150 * 300 \mathrm{~mm}$ & 36.8 & 100 & 0 \\
\hline & CYN-100-B & Су. $150 * 300 \mathrm{~mm}$ & 36.8 & 100 & 100 \\
\hline & CYN-100-C & Су. $150 * 300 \mathrm{~mm}$ & 36.8 & 100 & 200 \\
\hline & CYN-100-D & Су. $150 * 300 \mathrm{~mm}$ & 36.8 & 100 & 300 \\
\hline \multirow[t]{4}{*}{ Group-3 } & CYN-150-A & Су. $150 * 300 \mathrm{~mm}$ & 36.8 & 150 & 0 \\
\hline & CYN-150-B & Су. $150 * 300 \mathrm{~mm}$ & 36.8 & 150 & 100 \\
\hline & CYN-150-C & Су. $150 * 300 \mathrm{~mm}$ & 36.8 & 150 & 200 \\
\hline & CYN-150-D & Су. $150 * 300 \mathrm{~mm}$ & 36.8 & 150 & 300 \\
\hline \multirow[t]{4}{*}{ Group-4 } & CYH-100-A** & Су. $150 * 300 \mathrm{~mm}$ & 52.6 & 100 & 0 \\
\hline & CYH-100-B & Су. $150 * 300 \mathrm{~mm}$ & 52.6 & 100 & 100 \\
\hline & $\mathrm{CYH}-100-\mathrm{C}$ & Су. $150 * 300 \mathrm{~mm}$ & 52.6 & 100 & 200 \\
\hline & CYH-100-D & Су. $150 * 300 \mathrm{~mm}$ & 52.6 & 100 & 300 \\
\hline
\end{tabular}

jassim24676@uomosul.edu.iq;_sua269@gmail.com;_ odaycivileng@uomosul.edu.iq 790 * Corresponding author: College of Engineering, University of Mosul, Mosul, Iraq 
Journal of University of Duhok, Vol.23, No.2 (Pure and Eng. Sciences),Pp 788-799, 2020 (Special Issue)

$3^{\text {rd }}$ international conference on recent innovations in engineering (ICRIE) Duhok, September 9-10-2020

\begin{tabular}{|c|c|c|c|c|c|}
\hline \multirow[t]{4}{*}{ Group-5 } & CYH-150-A & Су. $150 * 300 \mathrm{~mm}$ & 52.6 & 150 & 0 \\
\hline & CYH-150-B & Су. $150 * 300 \mathrm{~mm}$ & 52.6 & 150 & 100 \\
\hline & CYH-150-C & Су. $150 * 300 \mathrm{~mm}$ & 52.6 & 150 & 200 \\
\hline & CYH-150-D & Су. $150 * 300 \mathrm{~mm}$ & 52.6 & 150 & 300 \\
\hline \multirow[t]{2}{*}{ Group-6 } & CUN-50-A ${ }^{* * *}$ & Cube $150 \mathrm{~mm}$ & 36.8 & 50 & 0 \\
\hline & CUN-50-B & Cube $150 \mathrm{~mm}$ & 36.8 & 50 & 150 \\
\hline \multirow[t]{2}{*}{ Group-7 } & CUN-75-A & Cube $150 \mathrm{~mm}$ & 36.8 & 75 & 0 \\
\hline & CUN-75-B & Cube $150 \mathrm{~mm}$ & 36.8 & 75 & 150 \\
\hline \multirow[t]{2}{*}{ Group-8 } & CUN-100-A & Cube $150 \mathrm{~mm}$ & 36.8 & 100 & 0 \\
\hline & CUN-100-B & Cube $150 \mathrm{~mm}$ & 36.8 & 100 & 150 \\
\hline \multirow[t]{2}{*}{ Group-9 } & CUN-150-A & Cube $150 \mathrm{~mm}$ & 36.8 & 150 & 0 \\
\hline & CUN-150-B & Cube $150 \mathrm{~mm}$ & 36.8 & 150 & 150 \\
\hline
\end{tabular}

\section{Nomenclatures of specimens:}

* CYN-(50, 100 \& 150) -(A, B, C \& D) means cylindrical specimens prepared using normal strength concrete are applied to limited areas with size $(50,100 \& 150 \mathrm{~mm})$ and the CFRP wrapped lengths are $(0,100,200$ and $300 \mathrm{~mm})$ as depicted in Figure 1.

** CYH-(100 \& 150) -(A, B, C \& D) means cylindrical specimens prepared using high strength concrete are applied to limited areas with size $(100 \& 150 \mathrm{~mm})$ and the CFRP wrapped lengths are $(0,100,200$ and $300 \mathrm{~mm})$.

*** CUN-(50,75, $100 \& 150)$-(A \& B) means cubic specimens prepared using normal strength concrete are applied to limited areas with size $(50,75,100 \& 150 \mathrm{~mm})$ and the CFRP wrapped lengths are $(0$, and 150mm) as depicted in Figure 1.

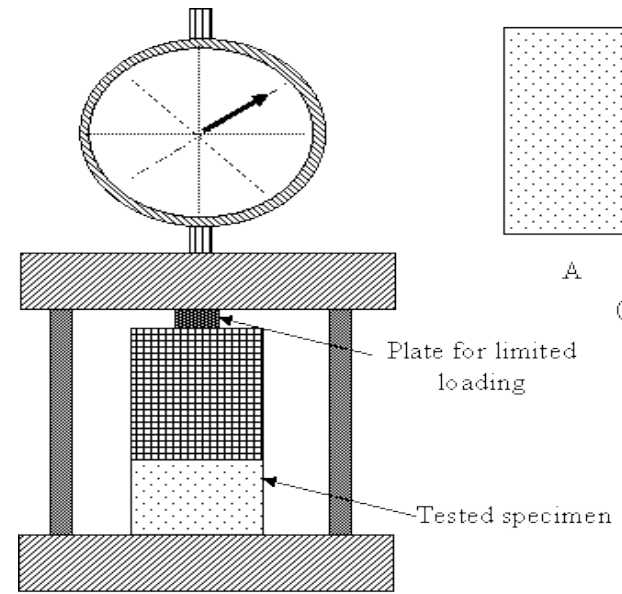

(a) Test Setup

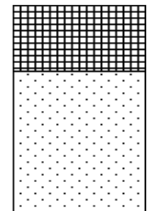

B

b) Wrapped and unwrapped Cylinders

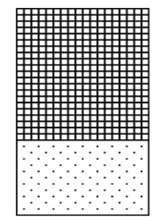

$\mathrm{C}$

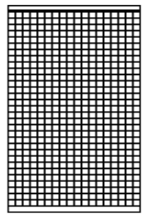

D

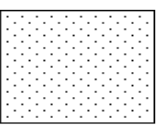

$\dot{A}$

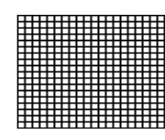

B

(c) Wrapped and unwr apped Cubes

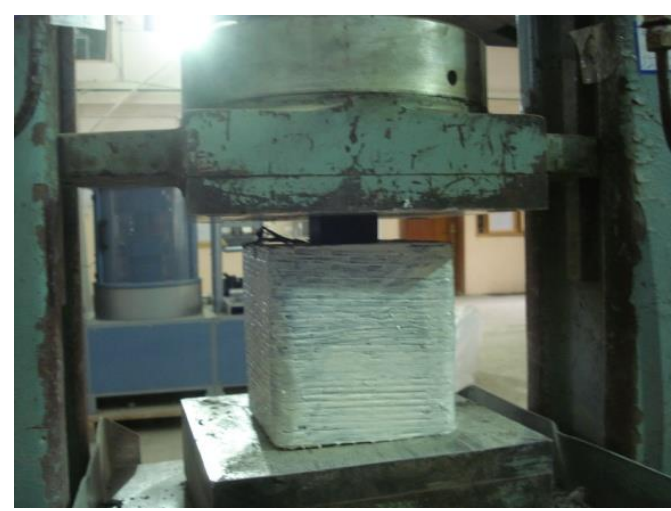

(d) Photo of Test-Setup

Fig. (1): Schematic of test setup and specimens wrapping details

jassim24676@uomosul.edu.iq; sua269@gmail.com; odaycivileng@uomosul.edu.iq

* Corresponding author: College of Engineering, University of Mosul, Mosul, Iraq 


\section{FAILURE MODES}

For comparison, each group adopted herein includes exposed specimens applied to localized compressive loads were also examined as depicted in Table (1). For both cubic and cylindrical exposed specimens, the limited compression size of loading area is $(50,100$ and $150 \mathrm{~mm}$ ). The Figures (2-4) show the failure shapes of tested specimens. It was depicted that, for exposed concrete specimen, the splitting radial cracks firstly appeared at the loading face. The cracks then extend from perimeter of the loading area to the edge of the specimens. Finally, the cracks progressed toward the bottom of the specimens. While the axial loads increased, some cracks elongated and widened. The failure mode attends to be splitting failure due to the perforation of the specimens. It was also depicted that there were several spread cracks having the same orientation, and the cracks pass through the aggregate at the high stress zone near the steel bearing plate. The splitting cracks couldn't penetrate the loading plane because of the existing of the frictional confinement. Finally, an inverse conical shape or pyramid below the bearing plate was formed.

During the test time, it was shown that the performance of wrapped specimens using CFRP was more ductile than that un-wrapped, that reveled the confining using CFRP is efficient for specimens applied to limited areas of loading. The wrapped specimens of normal concrete have obvious mode of failures as shown in Figure 2(bd). The failure mode of specimen CYN-50-B is splitting failure, the specimen cut to two halves and the CFRP was ruptured longitudinally. The failure mode of CYN-100-C shows that the CFRP ruptured at upper third of the specimen. This may be revealed that the confining using CFRP was active to the level of the size of the loading area. The failure mode of CYN-150-D is depicted in Figure (2-d), as shown the CFRP ruptured at approximately the intermediate two third of the specimen due to lateral deformation of specimen, that may be revealed the high efficiency of CFRP confining of concrete specimens.

The Figure (3) shows the failure modes of high strength concrete specimens. The Figure (3-a) depicts the exposed CYH-100-A specimen. As shown, the cracks were longitudinal and penetrate under the loading plane due to spalling off the concrete cover and absence the frictional confinement.

The Figure 3(b-c) show the failure mode of specimens CYH-100-B and CYH-100-D, that revealed that the confining of specimens using CFRP is efficient at the upper third of the height of the specimens or at least at level of the size of the loading area. While the failure mode of $\mathrm{CYH}-$ 150-C in Figure (3-d) revealed that the exposed part of specimen was exhibited to bearing failure and the upper two third of height were confined efficiently.

The failure modes of normal concrete cubes tested under limited loading area are shown in Figure (4). As depicted in Figure (4-a) for exposed specimen, the splitting cracks at once started near of the loading face, then The cracks extend from the corner of the applied loading area to the edges of the specimens. Then, the cracks developed toward the bottom of the specimens. The Figure (4-b) depicts the failure mode of the specimen CUN-50-B, as shown the cracks started from the corners of the loading area to the corners of the specimen and the loading area penetrate the surface of loading as well as the CFRP was ruptured at the upper half of the height of specimen. That reveled; the CFRP confining is efficient at the part of specimen near of the loading area. The failure modes of specimens CUN-100-B and CUN-150-B are depicted in Figure c\& d. As shown, the CFRP was ruptured and the concrete cover was spalled off and stayed pasted to the CFRP. That revealed the higher efficiency of CFRP confinement. 


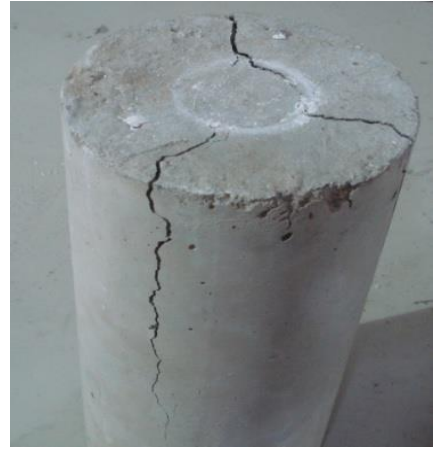

(a) CYN-50-A

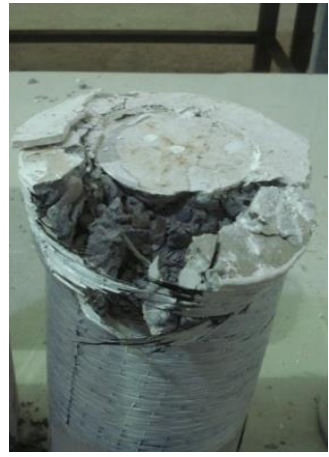

(c) $\mathrm{CYN}-100-\mathrm{C}$

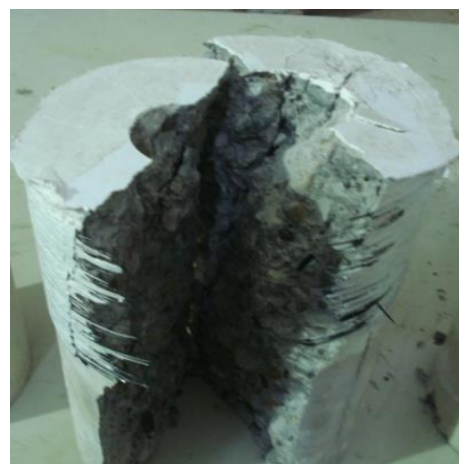

(b) $\mathrm{CYN}-50-\mathrm{B}$

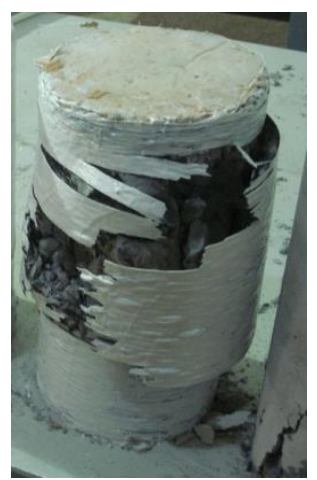

(d) CYN-150-D

Fig. (2): Failure modes of normal strength cylinders with different wrapping length and area of loading.

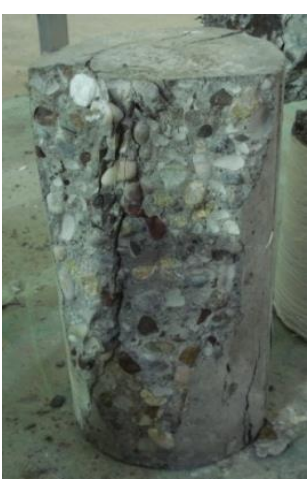

(a) CYH-100-A

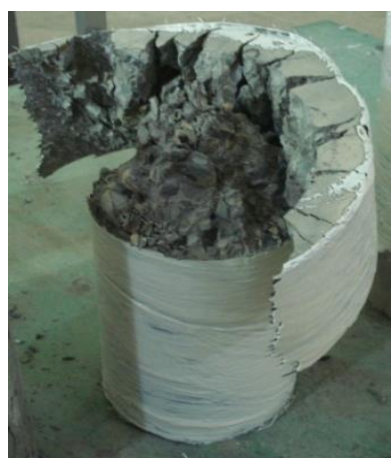

(c) CYH-100-D

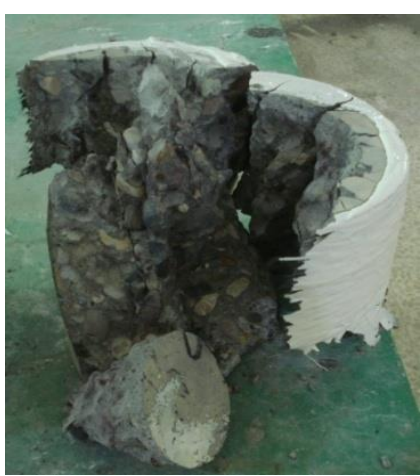

(b) CYH-100-B

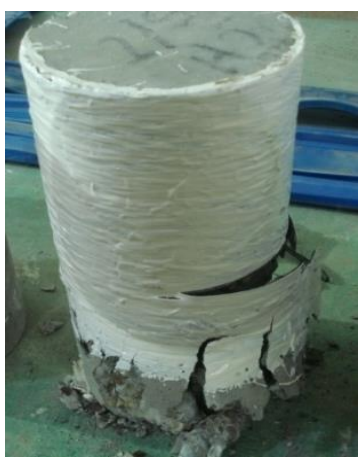

(d) $\mathrm{CYH}-150-\mathrm{C}$

Fig. (3): Failure modes of high strength cylinders with different wrapping length and area of loading.

jassim24676@uomosul.edu.iq; sua269@gmail.com;_ｏdaycivileng@uomosul.edu.iq

* Corresponding author: College of Engineering, University of Mosul, Mosul, Iraq 


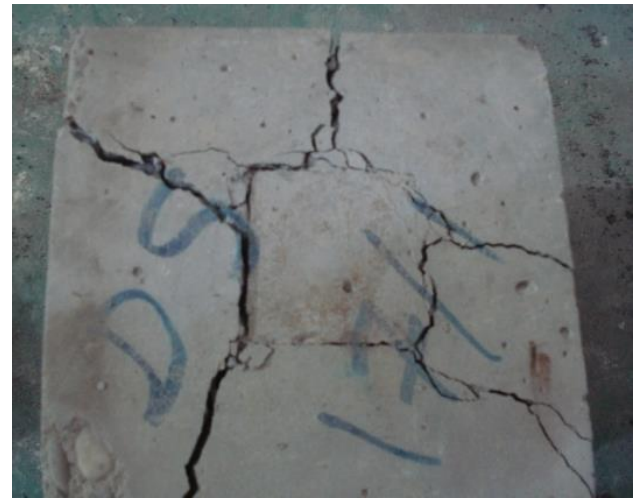

(a) CUN-50-A

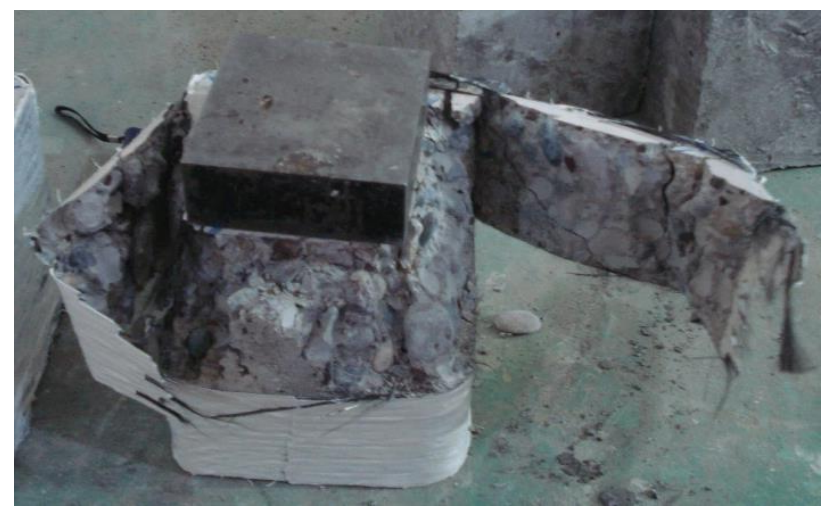

(c) CUN-100-B

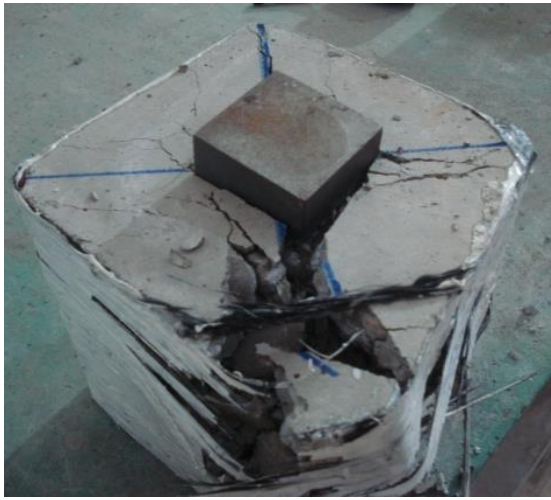

(b) CUN-50-B

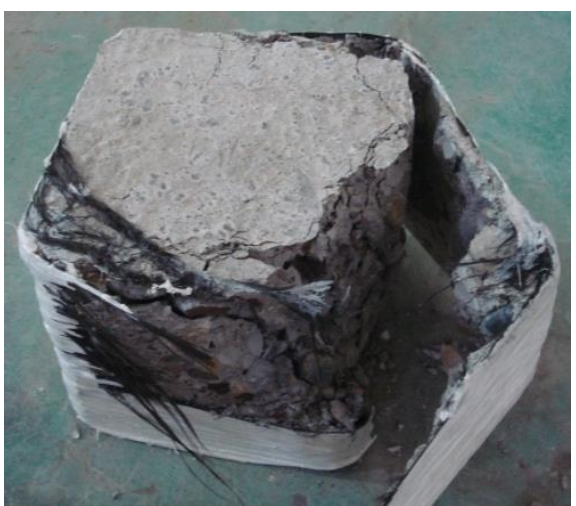

(d) CUN-150-B

Fig. (4): Failure modes of normal strength cubes with and without wrapping and different loading area.

\section{RESULTS AND DISCUSSION}

The experimental results are summarized in Table (2) and Figures (5-8). Table 2 depicts the load carrying capacity $(\mathrm{P})$ of the tested specimens, the bearing strength of tested specimens and bearing strength ratio of wrapped specimens using CFRP $\left(\sigma_{\mathrm{B}} / \sigma_{\mathrm{BO}}\right)$ (i.e. Bearing strength of wrapped specimen to that exposed). The relationships among $\left(\sigma_{\mathrm{B}} / \sigma_{\mathrm{BO}}\right)$ ratio, the strength ratio $\left(\sigma_{\mathrm{B}}\left(f_{c}^{\prime}\right)\right)$ and bearing shape ratio $\left(\sqrt{ }\left(\mathrm{A}_{\mathrm{g}} / \mathrm{A}_{\mathrm{B}}\right)\right.$ : the square root of the total area to the loaded area) are depicted in Table 2, that illustrate the CFRP wrapped specimens have significantly higher localized loading strength compared to exposed specimens. It is also indicated that the bearing strength ratio is improved, as the bearing shape ratio increased for both CFRP wrapped and exposed specimens. The increasing of loading area leads to decreasing the bearing shape ratio as well as the wrapping of the concrete core improved the applied load. For smaller localized area of loading, the specimens confined using larger length of wrapping provides higher bearing capacity than those of short wrapping. 
Table (2): Results of Tested Specimens

\begin{tabular}{|c|c|c|c|c|c|c|c|}
\hline Group & Specimen & fc'(MPa) & $\sqrt{A_{g} / A_{B}}$ & $P(k N)$ & $\sigma_{\mathrm{B}}(\mathrm{MPa})$ & $\sigma_{\mathrm{B}} / \sigma_{\mathrm{BO}}$ & $\sigma_{\mathrm{B}} / \mathbf{f}_{\mathrm{c}}^{\prime}$ \\
\hline \multirow[t]{4}{*}{ Group-1 } & CYN-50-A & 36.8 & 3 & 300 & 152.8 & 1.00 & 4.2 \\
\hline & CYN-50-B & 36.8 & 3 & 320 & 163.0 & 1.07 & 4.4 \\
\hline & CYN-50-C & 36.8 & 3 & 420 & 213.9 & 1.40 & 5.8 \\
\hline & CYN-50-D & 36.8 & 3 & 300 & 152.8 & 1.00 & 4.2 \\
\hline \multirow[t]{4}{*}{ Group-2 } & CYN-100-A & 36.8 & 1.5 & 310 & 39.5 & 1.00 & 1.1 \\
\hline & CYN-100-B & 36.8 & 1.5 & 500 & 63.7 & 1.61 & 1.7 \\
\hline & CYN-100-C & 36.8 & 1.5 & 430 & 54.8 & 1.39 & 1.5 \\
\hline & CYN-100-D & 36.8 & 1.5 & 500 & 63.7 & 1.61 & 1.7 \\
\hline \multirow[t]{4}{*}{ Group-3 } & CYN-150-A & 36.8 & 1 & 650 & 36.8 & 1.00 & 1.0 \\
\hline & CYN-150-B & 36.8 & 1 & 690 & 39.0 & 1.06 & 1.1 \\
\hline & CYN-150-C & 36.8 & 1 & 850 & 48.1 & 1.31 & 1.3 \\
\hline & CYN-150-D & 36.8 & 1 & 920 & 52.1 & 1.41 & 1.4 \\
\hline \multirow[t]{4}{*}{ Group-4 } & CYH-100-A & 52.6 & 1.5 & 500 & 63.7 & 1.00 & 1.2 \\
\hline & CYH-100-B & 52.6 & 1.5 & 780 & 99.3 & 1.56 & 1.9 \\
\hline & $\mathrm{CYH}-100-\mathrm{C}$ & 52.6 & 1.5 & 810 & 103.1 & 1.62 & 2.0 \\
\hline & CYH-100-D & 52.6 & 1.5 & 810 & 103.1 & 1.62 & 2.0 \\
\hline \multirow[t]{4}{*}{ Group-5 } & CYH-150-A & 52.6 & 1 & 930 & 52.6 & 1.00 & 1.0 \\
\hline & CYH-150-B & 52.6 & 1 & 1010 & 57.2 & 1.09 & 1.1 \\
\hline & CYH-150-C & 52.6 & 1 & 1100 & 62.2 & 1.18 & 1.2 \\
\hline & CYH-150-D & 52.6 & 1 & 1200 & 67.9 & 1.29 & 1.3 \\
\hline \multirow[t]{2}{*}{ Group-6 } & CUN-50-A & 36.8 & 3 & 300 & 120.0 & 1.00 & 3.3 \\
\hline & CUN-50-B & 36.8 & 3 & 400 & 160.0 & 1.33 & 4.3 \\
\hline \multirow[t]{2}{*}{ Group-7 } & CUN-75-A & 36.8 & 2 & 400 & 71.1 & 1.00 & 1.9 \\
\hline & CUN-75-B & 36.8 & 2 & 570 & 101.3 & 1.43 & 2.8 \\
\hline \multirow[t]{2}{*}{ Group-8 } & CUN-100-A & 36.8 & 1.5 & 750 & 75.0 & 1.00 & 2.0 \\
\hline & CUN-100-B & 36.8 & 1.5 & 1000 & 100.0 & 1.33 & 2.7 \\
\hline \multirow[t]{2}{*}{ Group-9 } & CUN-150-A & 36.8 & 1 & 900 & 40.0 & 1.00 & 1.1 \\
\hline & CUN-150-B & 36.8 & 1 & 1200 & 53.3 & 1.33 & 1.4 \\
\hline
\end{tabular}

The $\left(\sigma_{\mathrm{B}} / \sigma_{\mathrm{BO}}\right)$ ratio demonstrates the influence of CFRP wrapping length on the bearing resistance for the adopted loading areas. As shown in the table, the $\left(\sigma_{\mathrm{B}} / \sigma_{\mathrm{BO}}\right)$ ratio of the wrapped specimens with larger area of loading is greater than that of the smaller area (size $50 \mathrm{~mm}$ ). Furthermore, the $\left(\sigma_{\mathrm{B}} / \sigma_{\mathrm{BO}}\right)$ ratio of specimens with small areas of loading (size $50 \& 100 \mathrm{~mm}$ ) is not affected by the length of wrapping that is revealed the full wrapping length isn't need for specimens loaded by small areas. Figure (5) depicts the size of localized loading area versus bearing strength curves of normal concrete specimens with different lengths of CFRP wrapping that illustrate the bearing strength of the smaller size of loading area is greater than that of others as well as the full length of wrapping is not very effective specially for specimens applied to the loads on small areas due to limited confining action near of the bearing area (i.e. the effective confinement is occurred approximately in the upper part of the height of specimens). The Figure (6) shows the jassim24676@uomosul.edu.iq;_sua269@gmail.com;_ odaycivileng@uomosul.edu.iq * Corresponding author: College of Engineering, University of Mosul, Mosul, Iraq 
relationship of bearing strength versus size of loading area of specimens prepared of high strength concrete with various length of wrapping. The figure proves that wrapped specimens provide a bearing strength better than exposed specimens and the length of wrapping not affected the bearing strength of wrapped specimens especially that loaded using smallest loading area. Figure (7) depicts the relationship between the size of loading area and the bearing strength of wrapped and unwrapped cubes. As shown in the figure, the bearing strength of the confined specimens is developed better than that unconfined specimens, which indicates the high efficiency of CFRP wrapping. The Table 2 and Figure (8) depict the relationship between the
$\left(\sigma_{\mathrm{B}} / f_{c}^{\prime}\right)$ ratio and the $\sqrt{ }\left(\mathrm{A}_{\mathrm{g}} / \mathrm{A}_{\mathrm{B}}\right)$ ratio of specimens. As illustrated in the table and the figure, the $\left(\sigma_{\mathrm{B}} / f_{c}{ }^{\prime}\right)$ ratio of high strength concrete specimens is greater than that of the normal concrete specimens for the same $\sqrt{ }\left(\mathrm{A} g_{g} / \mathrm{A}_{\mathrm{B}}\right)$ ratio that revealed the bearing strength of high strength concrete progresses faster than that of normal concrete specimens, which indicates that the high strength concrete provides a bearing strength higher than that of normal concrete relative to the compressive strength progressing. Relatively, the specimens with higher compressive strength provide higher bearing strength with different ratio of increasing the compressive strength of concrete.

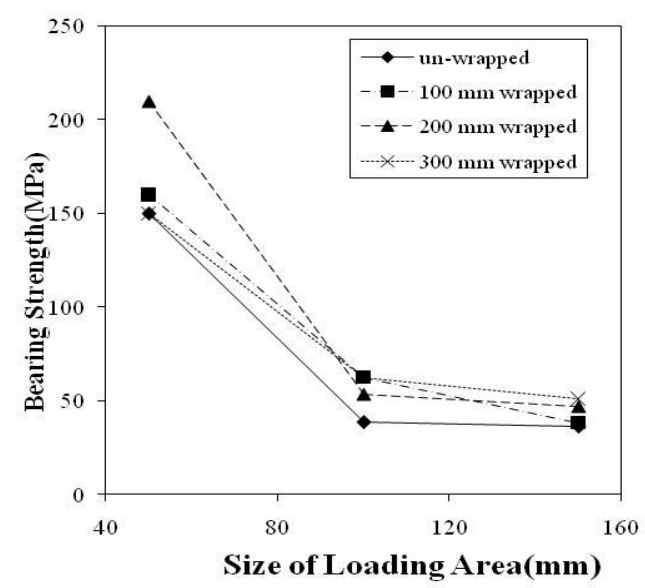

Fig. (5): Bearing strength Vs. Size of loading curves of normal concrete Cylinders with different lengths of CFRP wrapping.

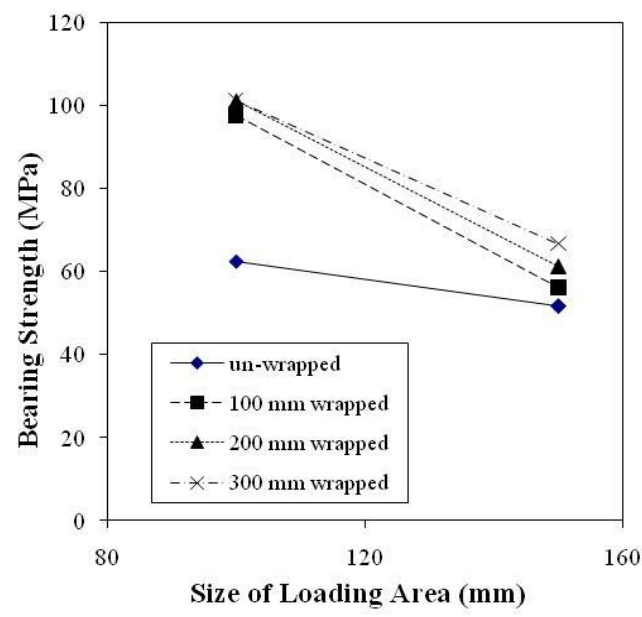

Fig. (6): Bearing strength Vs. Size of loading area curves of high strength concrete Cylinders with different

jassim24676@uomosul.edu.iq;_sua269@gmail.com;_ odaycivileng@uomosul.edu.iq 796 * Corresponding author: College of Engineering, University of Mosul, Mosul, Iraq 
lengths of CFRP wrapping.

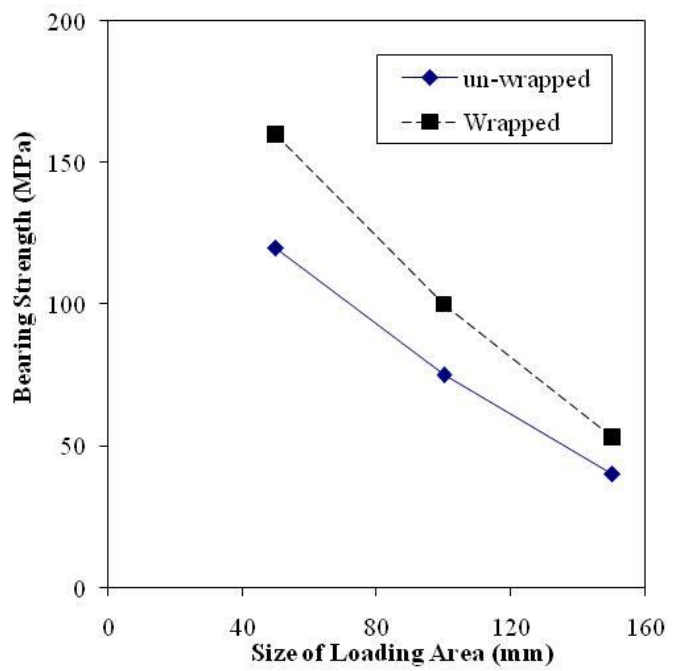

Fig. (7): Bearing strength Vs. Size of loading area curves of normal concrete Cubes wrapped and unwrapped by CFRP.

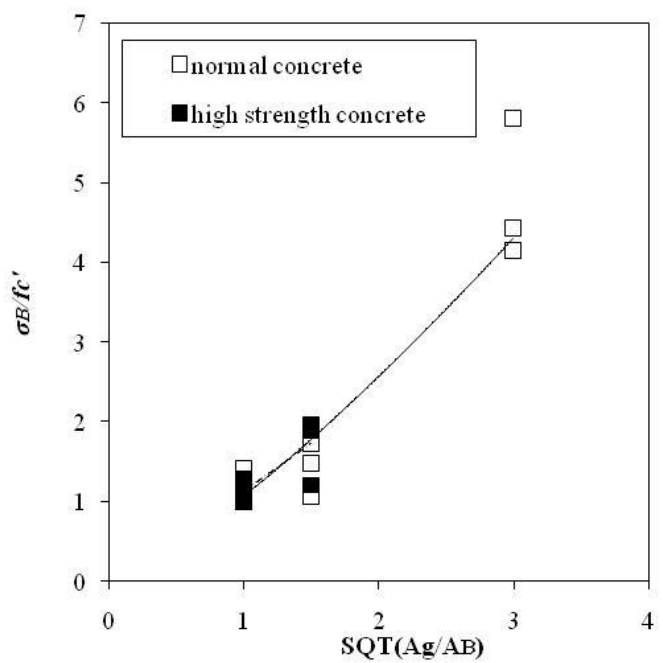

Fig. (8): Strength ratio Vs. Bearing shape ratio curves of deferent strength concrete specimens.

\section{CONCLUSIONS}

The localized loading resistance of CFRP wrapped cylindrical and cubic concrete specimens was investigated by testing twenty-six specimens under partial loading areas. For comparison, the tested specimens included unwrapped specimens. The major items were the compressive strength and the length of CFRP wrapping. The failure modes and the testing results were extensively analyzed and the following findings can be mentioned:

1. The failure modes of normal concrete specimens illustrate that the performance of wrapped specimens was more ductile than those unwrapped and the confining is happened at the upper part of the specimen height, which indicates that the confining using CFRP is efficient but the full wrapping of specimens isn't required.

jassim24676@uomosul.edu.iq;_sua269@gmail.com;_ odaycivileng@uomosul.edu.iq

* Corresponding author: College of Engineering, University of Mosul, Mosul, Iraq 
2. The failure modes of high strength specimens showed that the wrapped specimens behaved better than those unwrapped and the efficiency of wrapping is evident at the upper third of the height but it need to full wrapped to prevent the bearing failure for exposed area of the short height of wrapping.

3. From the test results, the CFRP wrapped specimens provided higher localized loading resistance compared to exposed specimens.

4. The bearing strength ratio improved as the bearing shape ratio increased for both CFRP wrapped and exposed specimens.

5. The increasing of loading area leads to decreasing the bearing shape ratio as well as the wrapping of the concrete core improves the applied load.

6 . The bearing strength ratio of specimens with small bearing areas is not affected by the length of CFRP wrapping that indicates the full wrapping is not required for specimens loaded using smaller areas.

7. The high strength concrete manifests higher progressing of bearing strength, which indicates the strength of concrete affects the progressing of bearing strength obviously.

\section{Acknowledgment}

The authors would like to express their gratitude to the Dean of the College of Engineering at University of Mosul for his encouragement.

\section{REFERENCES}

Jasim Ali Abdullah, Zhang Sumei, Liu Jiepeng (2010), "Shear strength and behavior of tubed reinforced and steel reinforced concrete (TRC and TSRC) short columns", Thin-Walled Structures, $\quad$ 48(3), 191-199. https://10.1016/j.tws.2009.11.002 .

Jiepeng Liu, Jasim Ali Abdullah, Sumei Zhang (2011), "Hysteretic behavior and design of square tubed reinforced and steel reinforced concrete (STRC and/or STSRC) short columns", ThinWalled Structures, 49(7), 874-888. https://10.1016/j.tws.2011.02.012 .

G. Ganesh Prabhu, M.C., Sundarraja (2013), "Behavior of concrete filled steel tubular (CFST) short columns externally reinforced using CFRP strips composite jackets", Construction and Building Materials, 47, 13621371 .

https://10.1016/j.conbuildmat.2013.06.038 .

Mirmiran Amir, Shahawy Mohsen, Samaan Michel, El Echary Hazem, Juan Carlos Mastrapa and Odell Pico (1998), "Effect of Column Parameters on FRP Confine concrete", Journal of Composite Construction, 2(4), 175-85. https://doi.org/10.1061/(ASCE)10900268(1998)2:4(175) .

Xiao Y, Wu H. (2000), "Compressive behavior of concrete confined by carbon fiber composite jackets", J Mater Civil Eng, 12(2),139-0146. ISSN 0899-1561/00/0002-0139-0146.

Pantazopoulou SJ, Bonacci JF, Sheikh S, Thomas MDA, Hearn N. (2001), "Repair of CorrosionDamaged Columns with FRP Wraps", J Compos Constr, 5, 003-11. ISSN 10900268/01/0001-0003-0011

Mukherjee A, Boothby TE, Bakis CE, Joshi MV, Maitra SR. (2004), "Mechanical behavior of fiber-reinforced polymer-wrapped concrete columns-complicating effects", J Compos Constr, 8(2), 097-103. https://doi.org/10.1061/(ASCE)10900268(2004)8:2(97)

Yalcin Cem, Kaya Osman, Sinangil Mustafa (2006), "Seismic retrofitting of $\mathrm{R} / \mathrm{C}$ columns having plain rebars using CFRP sheets for improved strength and ductility", Constr Build Mater, 22, 295-307.

https://10.1016/j.conbuildmat.2006.08.017 .

Ye LP, Zhang K, Zhao SH, and Feng P. (2003), "Experimental study on seismic strengthening of RC columns with wrapped CFRP sheets", Constr Build Mater, 17, 499-506. https://10.1016/S0950-0618(03)00047-3

Pankaj Agarwal, Ankit Gupta, Rachanna G. Angadi (2014), "Effect of FRP wrapping on axial

jassim24676@uomosul.edu.iq;_sua269@gmail.com;_ｏdaycivileng@uomosul.edu.iq 798 * Corresponding author: College of Engineering, University of Mosul, Mosul, Iraq 
behavior of concrete and cyclic behavior of external RC beam column joints", KSCE Journal of Civil Engineering, 18(2), 566-573. https://doi.org/10.1007/s12205-014-0259-y.

Mehdi M. Lima, Jeung-Hwan Doh, Muhammad N. S. Hadi and Dane Miller (2016), "The effects of CFRP orientation on the strengthening of reinforced concrete structures", THE STRUCTURAL DESIGN OF TALL AND SPECIAL BUILDINGS, April 2016. https://10.1002/tal.1282 .

Yaman Sami Shareef Al-Kamaki, Gulan Bapeer Hassan, Gehan Alsofi (2018), "Experimental study of the behavior of RC corbels strengthened with CFRP sheets", Case Studies in Construction Materials, 9, 1-10. https://doi.org/10.1016/j.cscm.2018.e00181 .

Saja Waleed Fathuldeen and Musab Aied Qissab (2019), " Behavior of RC beams strengthened with NSM CFRP strips under flexural repeated loading", Structural Engineering and Mechanics, 70 (1), 67-80, DOI: https://doi.org/10.12989/sem.2019.70.1.067 .

Tae Won Park, Ung Jin Na, Lan Chung, Maria Q. Feng (2008), "Compressive behavior of concrete cylinders confined by narrow strips of CFRP with spacing", Composites Part B: Engineering, 39(7-8), $1093-1103$. https://10.1016/j.compositesb.2008.05.002 .

A. R. Khan,N. S. Zafar (2010), "Compressive Strength of Concrete Cylinders Confined with CFRP Wraps", CICE 2010 - The 5th International Conference on FRP Composites in Civil Engineering, Beijing, China, September.

R. Sri Ravindrarajah , Rhesa Reinaldy (2010), "Bearing Strength of CFRP Confined Concrete", CICE 2010 - The 5th International Conference on FRP Composites in Civil Engineering, Beijing, China, September.

Fouad Khairallah (2013), "Mechanical behavior of confined self-compacting reinforced concrete circular columns under concentric axial loading", Ain Shams Engineering Journal, 4(1), http://dx.doi.org/10.1016/j.asej.2013.01.009.
Pedram Sadeghian, Brandon Fillmore (2018), " Strain distribution of basalt FRP-wrapped concrete cylinders", Case Studies in Construction Materials, https://doi.org/10.1016/j.cscm.2018.e00171

Marina L. Moretti (2019), " Effectiveness of different confining configurations of FRP jackets for concrete columns", Structural Engineering and Mechanics, 72 (2), 155-168, DOI: https://doi.org/10.12989/sem.2019.72.2.155

Rafael Alves de Souza, Leandro Mouta Trautwein and Mauricio de Pina Ferreira (2019), "Reinforced Concrete Corbel Strengthened Using Carbon Fiber Reinforced Polymer (CFRP) Sheets", Journal of Composite Science, 3(1). https://doi.org/10.3390/jcs3010026 .

jassim24676@uomosul.edu.iq; sua269@gmail.com; odaycivileng@uomosul.edu.iq

* Corresponding author: College of Engineering, University of Mosul, Mosul, Iraq 